1 Doutorando em Nutrição em Saúde Pública pela Universidade de São Paulo (USP) - São Paulo (SP), Brasil.

leandromtg@gmail.com

2 Doutoranda em Saúde Púbica pela Universidade de São Paulo (USP) - São Paulo (SP), Brasil. iadya@yahoo.com.br

3 Mestranda em Nutrição em Saúde Pública pela Universidade de São Paulo (USP) - São Paulo (SP), Brasil.

tayna.ishii@gmail.com

4 Graduação em Fisioterapia pela Escola Superior de Tecnologias de Saúde do Porto - Porto, Portugal.

bourlinova@gmail.com

5 Doutora em Saúde Pública pela Universidade de São Paulo (USP) -

São Paulo (SP), Brasil. Professora da Universidade de São Paulo (USP) - São

Paulo (SP), Brasil.

hwatanab@usp.br

\section{Intersetorialidade na saúde no Brasil no início do século XXI: um retrato das experiências}

\author{
Intersectorality in health in Brazil at the beginning of the XXI \\ century: a portrait of experiences
}

Leandro Martin Totaro Garcia1, ladya Gama Maio², Taynã Ishii dos Santos³, Catarina Bourlinova de Jesus Cunha Folha4, Helena Akemi Wada Watanabe ${ }^{\mathbf{5}}$

RESUMO O objetivo foi investigar experiências de intersetorialidade voltadas aos problemas de saúde pública, iniciadas a partir de 2001, no Brasil. Para tanto, fez-se uma revisão utilizando a base de referências Lilacs, por meio de seleção de relatos de ações intersetoriais que abordassem problemas de saúde pública no País e que envolvessem o setor saúde. Onze artigos foram incluídos, em que se observaram falta de definição de intersetorialidade, parceria com o setor educação em dez projetos e raras avaliações de impacto e sustentabilidade. Mais informações sobre ações intersetoriais são urgentes para avaliar seu impacto, entender barreiras e limitações comuns e caminhos que as tornem mais efetivas.

PALAVRAS-CHAVE Ação intersetorial; Administração de serviços de saúde; Políticas, planejamento e administração em saúde.

ABSTRACT The aim was to investigate intersectorality experiences directed to public health problems, initiated from 2001 in Brazil. Therefore, a review was conducted using the Lilacs reference basis, selecting intersectoral action descriptions that had approached public health problems in the country and that had involved the Health sector. Eleven articles were included, in which were observed lack of intersectorality definition, partnership with the Education sector in ten projects and rare impact and sustainability assessments. More information about intersectoral actions are urgent in order to evaluate their impact, to understand common barriers and limitations, and ways to make them more effective.

KEYWORDS Intersectoral action; Health services administration; Health policy, planning and management. 


\section{Introdução}

Para muitas pessoas, ter saúde costuma ser a ausência de uma enfermidade ou doença. Esse enfoque evoca um conceito reducionista, ou seja, a reprodução do modelo biologicista, monopolizado pela medicina. Em contrapartida, diversos esforços vêm sendo realizados no sentido de posicionar a saúde a partir de outro olhar, mais ampliado e mais articulado com a complexidade da realidade. Embora existam discussões sobre a viabilidade da aplicação dessas definições de saúde, um conceito amplo de saúde evoca muito mais do que simplesmente garantir a disponibilidade e o acesso aos serviços de saúde. Enquanto fenômeno ampliado, a saúde depende da articulação que é produzida entre os seus diversos determinantes, tais como as condições de vida, de trabalho, do meio ambiente e da cultura, entre outros (NARVAl; FRAZÃO, 2008; DALMOLIN ET AL., 2011), sendo imprescindível, assim, considerar a promoção da saúde como o processo resultante de um conjunto de ações intersetoriais (Buss, 2000).

A intersetorialidade pode ser definida como a integração de diversos saberes e experiências de diferentes sujeitos e serviços sociais que contribuem nas decisões de processos administrativos para o enfrentamento de problemas complexos, com ações voltadas aos interesses coletivos que melhoram a eficiência da gestão política e dos serviços prestados (JUNQUEIRA, 2000; INOJOSA, 2001; NASCIMENTO, 2010). Logo, desenvolver estratégias e ações intersetoriais envolve atuar com diferentes sujeitos e serviços sociais, que, por meio de saberes, poderes e vantagens para resolver problemas complexos (INOJOSA, 2001), constroem uma nova concepção de planejamento, execução e controle dos serviços prestados, que objetiva garantir tratamento equânime às pessoas (JUNQUEIRA, 2000). Trabalhar de modo intersetorial significa superar a fragmentação do conhecimento e da prática e buscar a unidade e a diversidade para melhor compreensão da realidade (MENDES; ACKERMAN, 2007).

A construção da intersetorialidade se dá a partir da articulação de vários setores e envolve distintos atores sociais, tais como: governo, sociedade civil organizada, movimentos sociais, universidades, autoridades locais, setor econômico e mídia, tendo como preceito a reunião de vários saberes e possiblidades de atuação, no sentido de viabilizar um olhar mais amplo sobre a complexidade do objeto, a fim de possibilitar a análise dos problemas e das necessidades, no âmbito de um dado território e contexto (JUNQUEIRA, 1997), bem como a busca de soluções compartilhadas. A intersetorialidade é operacionalizada por meio da criação de uma rede de compromisso social, estruturada por vínculos e uma 'presença viva', na qual instituições, organizações e pessoas se articulam em torno de uma questão da sociedade em um determinado território, programam e realizam ações integradas e articuladas, avaliam juntos os resultados e reorientam a ação. Trata-se de um processo dialético e dinâmico, tendo a necessidade de se pôr em prática diferentes tipos de habilidades de negociação e de mediação de conflitos (PORTO; LACAZ; MACHADO, 2003), que implicam a abertura de cada setor envolvido para dialogar, formar vínculos, estabelecer corresponsabilidades e cogestão pela melhora da qualidade de vida da população (CAMPOS; BARROS; CASTRO, 2004).

Para tanto, faz-se necessária a mudança de paradigmas, de concepções, de práticas e de valores, para que o processo fragmentado seja alterado para a forma intersetorial, envolvendo, também, a população que vivencia o problema na busca de soluções compartilhadas. É preciso estar ciente de que nada acontecerá de potente pela simples junção de diferentes setores convocados por conta de uma situação problemática ou com a simples delegação de responsabilidade de um setor para o outro. Deve haver não só a 
partilha de conhecimentos e de experiências, mas, sobretudo, um compromisso de fato, pois uma rede não pode ser meramente protocolar (COUTO; DELGADO, 2010).

A vida atual demonstra como cada indivíduo e coletividade têm necessidades relativas a várias áreas: segurança, saneamento, moradia, alimentação, saúde, educação etc. Mais ainda, demonstra como essas áreas se influenciam. Como Inojosa (2001) e Mendes e Akerman (2007) mencionam, os determinantes da saúde são diversos e interdependentes. Se essas necessidades/determinantes formassem um simples somatório para a saúde e a qualidade de vida, uma mudança ou a falta em uma delas não alteraria a influência das restantes. No entanto, o ser humano é um todo, com os seus sistemas, segmentos, emoções, expetativas e memórias, e o seu bem-estar, desenvolvimento e qualidade de vida estão relacionados com todos esses componentes.

Desta forma, não é apenas a complexidade dos problemas que impõe a necessidade de ações intersetoriais. Pretende-se a complementariedade da ação humana, pois "a intersetorialidade [...] reconhece os domínios temáticos, comunicando-os para a construção de uma síntese" (MENDES, 1996, P. 253). Setores isolados não dão conta do que está tecido em conjunto, da complexidade ou da diversidade articulada (INOJOSA, 2001). Sem dúvida, as necessidades e expectativas das pessoas e dos grupos sociais, referentes à saúde e à qualidade de vida, são integradas.

Com a intersetorialidade, busca-se a superação de uma visão restrita de mundo e a compreensão da complexidade da realidade. O reconhecimento dos domínios temáticos propicia a sua comunicação para a construção de uma síntese. Esse seria o caminho para a sinergia nas políticas públicas (MENDES; ACKERMAN, 2007), para que haja unidade na diversidade, para que se procure um objetivo comum. Sem uma lógica de articulação e de coordenação entre setores, cada um irá propor seu próprio projeto, baseado em sua visão de realidade, e estabelecerá seus próprios objetivos e métodos. Desta forma, os resultados de uma ação apenas setorial são o agravamento de distorções, desigualdades e exclusão social (INOJOSA, 2001; MENDES; ACKERMAN, 2007).

No entanto, não obstante a reconhecida importância da intersetorialidade para o enfretamento dos problemas e das desigualdades em saúde, ainda pouco se sabe sobre a real operacionalização e os resultados de experiências mais recentes desse tipo no Brasil. Tal informação é necessária para que seja possível avaliar o impacto dessas ações no País, assim como entender barreiras e limitações comuns a serem superadas e identificar caminhos que tornem tais ações mais efetivas. Sendo assim, o objetivo deste trabalho foi investigar as experiências de intersetorialidade dedicadas a problemas de saúde pública que tenham sido realizadas desde 2001, no Brasil, assim como suas características e seus resultados.

\section{Método}

Trata-se de um trabalho de revisão, que seguiu procedimentos sugeridos pela Cochrane Collaboration (HIGGINS; GREEN, 2011). Os critérios de inclusão dos documentos analisados foram: abordar um problema de saúde pública; envolver o setor saúde; ter como objetivo relatar uma experiência de intersetorialidade; ocorrer no Brasil, em qualquer esfera da federação, podendo envolver mais de uma delas; referir-se a uma ação com início a partir de 2001; ter seu resumo disponível na base de referências Lilacs; estar publicado na forma de artigo completo, num periódico acadêmico; estar escrito no idioma português, espanhol ou inglês.

Decidiu-se, unicamente, pela utilização da base de referências Lilacs por ser “[...] o mais importante e abrangente índice da 
literatura científica e técnica da América Latina e Caribe" (LILACS, 2014). Na época em que a revisão ocorreu, mais de 850 periódicos e de 650 mil registros estavam disponíveis na base. Seu índice inclui periódicos indexados em outras bases importantes para a literatura acadêmica nacional, como a SciELO, mas sua abrangência vai além delas. A busca dos documentos foi realizada em 27 de março de 2013, utilizando o seguinte comando de busca, sem delimitação de índices: (intersectiona $\$$ OR intersetoria $\$$ OR intersectoria $\$ O R$ transectoria $\$$ OR transetoria $\$$ ) AND (health OR saúde OR salud). Como filtros, foram escolhidos o ano de publicação (2001 a 2013), o tipo de documento (artigos) e o assunto principal (ação intersetorial).

$\mathrm{Na}$ primeira etapa após a busca, foram lidos os títulos e resumos da totalidade dos textos. Os artigos que preencheram os critérios de inclusão ou que suscitaram dúvidas nos revisores quanto à sua exclusão imediata foram triados. Na etapa seguinte, os artigos triados foram obtidos na íntegra e examinados de acordo com os critérios de inclusão estabelecidos. Por fim, foram selecionados para a revisão os artigos que atingiram os critérios após a leitura integral dos manuscritos. Todo o processo ocorreu com cada artigo sendo avaliado por um par de revisores. Em qualquer etapa, nos casos em que estes tiveram opiniões discordantes sobre a manutenção de um determinado artigo para a etapa seguinte, uma reunião entre ambos foi realizada, e um consenso alcançado.

Dos artigos selecionados para a revisão, as seguintes informações foram obtidas: autores e ano de publicação do artigo; ação relatada; local e ano (ou período) da ação; principais objetivos da ação; setores/atores envolvidos; como a intersetorialidade ocorreu; resultados obtidos.

\section{Resultados e discussão}

A busca retornou 94 artigos. Desses, 31 (33\%) foram considerados elegíveis após a leitura de títulos e resumos. Após a leitura integral dos textos, verificou-se que 11 (12\%) preenchiam os critérios de elegibilidade, sendo incluídos na revisão. As poucas experiências descritas indicam que a construção de trabalhos compartilhados ainda é uma realidade pouco verificada. A tendência ainda é a da fragmentação e da descontinuidade política, com pouca participação popular, o que denota que a construção de redes e de ações interinstitucionais implica, também, a construção de uma nova linguagem integradora entre os campos profissionais e institucionais envolvidos.

O quadro 1 apresenta as informações obtidas de cada artigo. Pode-se observar que as publicações se referem a projetos de temas e objetivos variados, sendo três relacionados mais diretamente com o meio ambiente (PADULA ET AL., 2006; PARREIRA; SOUSA; NEVES, 2007; PALÁCIOS ET AL., 2012), três cujo problema principal foi a violência (CARNEIRO; GOMES, 2004; LOPES; MALFITANO, 2006; MAGALHÃES JUNIOR; OLIVEIRA, 2006) e três mais direcionados ao empowerment pessoal e comunitário (BECKER ET AL., 2004; SPERANDIO ET AL., 2006; MORI; OGATA, 2010). Os outros dois trabalhos tiveram foco no controle da dengue (FREITAS; RODRIGUES; ALMEIDA, 2011) e na redução das desigualdades sociais de forma mais ampla (DOBASHI ET AL., 2005). 
Quadro 1. Características das ações intersetoriais com foco em problemas de saúde pública no Brasil, realizadas e publicadas de 2001 a 2013

Becker et al., 2004. Iniciativa de Vila Paciência, Rio de Janeiro (RJ), de 2001 a 2003.

\section{Principais objetivos}

Empowerment pessoal e comunitário por meio da estratégia de Desenvolvimento Local Integrado Sustentável, com foco na Promoção da Saúde.

\section{Setores/atores envolvidos}

- Secretaria Municipal de Saúde;

- Centro de Promoção da Saúde;

- Grupo Gestor da Iniciativa de

Santa Cruz;

- Moradores do bairro.

\section{Como a intersetorialidade ocorreu}

- Oficinas participativas para construção de uma visão de futuro compartilhada; - Diagnóstico Comunitário Participativo;

- Pesquisas sobre a comunidade em fontes oficiais;

- Formatação de um instrumento de pesquisa domiciliar;

- Seminário Construção da Iniciativa de Vila Paciência;

- Acompanhamento, apoio e avaliação da rede de intervenções.

\section{Resultados}

- Agenda de Desenvolvimento Comunitário;

- Conjunto de 41 projetos de intervenção implementados em rede pelos participantes (a maioria é de moradores);

- Agrupamento de projetos que tinham convergência em seus objetivos;

- Capacitação dos autores de projetos como multiplicadores;

- Contato com órgãos públicos para projetos que necessitam de ações externas;

- Materiais para palestras e campanhas educativas produzidos com moradores da comunidade;

- Projetos selecionados para receber apoios financeiros.

\section{Carneiro e Gomes, 2004. Fórum de Combate à violência, Juazeiro (BA), de 2002 a 2004.}

\section{Principais objetivos Setores/atores envolvidos}

Promover estratégias de - Prefeitura Municipal de Juazeiro; redução dos índices de - Governo Estadual da Bahia;

mortalidade por causas - Escolas municipais;

externas;

- Elaborar e implantar um plano estratégico de fomento à cultura de paz;

- Levantar as condições demográficas e socioeconômicas da comunidade;

- Levantar o grau de participação da comunidade em movimentos sociais;

- Levantar os índices de situação de violência. ção;

- Órgãos da Justiça;

- Associação de moradores;

- Comerciantes.

\section{Como a intersetorialidade ocorreu}

- Apoio de recursos humanos, materiais, tecnológicos e financeiros da Secretaria Municipal de Saúde de Juazeiro e de entidades parceiras;

- Reuniões mensais;

- Realização de pesquisas bibliográficas e de visitas nas comunidades, instituições de saúde e outras.

\section{Resultados}

- Sistematização das estratégias que resultaram na identificação dos problemas do município;

- Aprovação do projeto Paz nas Escolas;

- Construção do subprojeto Violência e
Acidentes de Trânsito;

- Elaboração do Plano de Combate à Violência.

Dobashi et al., 2005. Projeto Viva Seu Bairro!, Campo Grande (MS), de 2001 a 2005.

\begin{tabular}{|c|c|c|c|}
\hline Principais objetivos & Setores/atores envolvidos & Como a intersetorialidade ocorreu & Resultados \\
\hline $\begin{array}{l}\text { Diminuir as desigual- } \\
\text { dades sociais. }\end{array}$ & $\begin{array}{l}\text { - Secretaria Municipal de Saúde; } \\
\text { - Secretaria Municipal de Educa- } \\
\text { ção; } \\
\text { - Secretaria Municipal de } \\
\text { Assistência Social; } \\
\text { - Secretaria Municipal de Habi- } \\
\text { tação; } \\
\text { - Secretaria Municipal de Trânsito; } \\
\text { - Secretaria Municipal de Obras; } \\
\text { - Secretaria Municipal de Planeja- } \\
\text { mento Urbano, } \\
\text { - Secretaria Municipal de Esporte, } \\
\text { Lazer e Cultura; }\end{array}$ & $\begin{array}{l}\text { - Coleta de dados durante as visitas } \\
\text { familiares realizadas pelas equipes do } \\
\text { Pacs/PSF; } \\
\text { - Análise dos dados pelos técnicos de } \\
\text { diversos setores da administração mu- } \\
\text { nicipal; } \\
\text { - Discussão nos sete conselhos regionais } \\
\text { urbanos, além dos setoriais; } \\
\text { - Mapeamento de } 32 \text { áreas, em todo o } \\
\text { perímetro urbano, por meio da seleção } \\
\text { de indicadores; } \\
\text { - Escolha de seis áreas de risco, para o } \\
\text { desenvolvimento da primeira etapa do } \\
\text { projeto; }\end{array}$ & $\begin{array}{l}\text { - Atendimento de } 37 \text { mil famílias, quase } \\
20 \% \text { da população total; } \\
\text { - Assentamento de populações ribeirinhas } \\
\text { em novas casas; } \\
\text { - Reconstrução de áreas degradadas, in- } \\
\text { cluindo educação ambiental nas escolas da } \\
\text { região e mobilização para a prática de ativi- } \\
\text { dades físicas e lazer; } \\
\text { - Construção e reforma de cinco Centros de } \\
\text { Múltiplo Uso; } \\
\text { - Geração de } 519 \text { empregos, capacitação } \\
\text { profissional de } 7 \text { mil pessoas e acesso a } \\
\text { crédito para } 120 \text { empresários; } \\
\text { - Regularização fundiária e titulação de } \\
\text { propriedade para } 880 \text { moradias; }\end{array}$ \\
\hline
\end{tabular}


Quadro 1. (cont.)

\section{Principais objetivos}

- Diminuir as desigualdades sociais.

\section{Setores/atores envolvidos}

- Agentes comunitários e profissionais das equipes do Programa Saúde da Família;

- Conselhos Regionais;

- Empresa Municipal de Habitação;

- Empresa Águas Guariroba;

- Agência Municipal de Emprego;

- Secretaria de Desenvolvimento

Econômico;

- Sebrae.

\section{Como a intersetorialidade ocorreu}

- Utilização de financiamento do BNDES e recursos próprios do Município;

- Criação de um Conselho Consultivo

formado por todos os secretários munici-

pais envolvidos

- Realização de oficinas de trabalho e

seminários de integração;

- Realização das Feiras de Amostras, geralmente no espaço de uma Escola Municipal, nas sete regiões urbanas, a fim de informar à população local o que estava programado para aquela região e como aconteceria, bem como seus custos. - Linha de trabalho denominada Melhorias Sanitárias Domiciliares (novas redes de água e esgoto, tanques de lavar roupa e lixeiras e a construção de 1.630 novas casas);

- Programa de controle da dengue que recolhia pneus para serem utilizado na construção de fossas;

- Fábrica da Gente: confeccão de manilhas e blocos para a construção de paredes; - Duas Oficinais de Saneamento que confeccionaram as instalações sanitárias.

\section{Resultados}

- Ampliação de 7 mil novas matrículas na alfabetização de jovens e adultos, além de 7.500 novas vagas nos ensinos pré-escolar e fundamental;

- Reassentamento de 750 famílias em situação de risco ambiental e recuperação de áreas degradadas;

- Pavimentação de 88 quilômetros e drenagem pluvial de mais 43 ruas, incluindo sinalização viária, identificação de ruas e instalação de abrigos em pontos de ônibus; - Construção de seis ginásios de esporte, sete quadras poliesportivas e 28 campos de futebol;

- Redução do número de casos de hepatite

A, meningite e diarreia;

- Aumento do cadastramento de diabéticos e hipertensos, com modificação do perfil para as formas leve e moderada;

- Redução do número de gestantes menores de 19 anos de idade, de 23\% para 18\%;

- Aumento da adesão de idosos às atividades de atenção integral à saúde.

Lopes e Malfitano, 2006. Projeto Rotas, Campinas (SP), 2004.

\section{Principais objetivos}

- Oferecer oficina de fotografia para adolescentes e crianças contra a violência sexual;

- Discutir, com base no território, as questões de exploração/violência sexual de crianças e jovens;

- Realizar ações de prevenção por meio de ações educativas, culturais, saudáveis e em perspectiva social.

\section{Setores/atores envolvidos}

- Ministério da Educação e Cultura, por intermédio da Secretaria de Ensino Superior e do Programa de Apoio à Extensão Universitária voltado às políticas públicas;

- Pró-Reitoria de Extensão da Universidade Federal de São Carlos; - Prefeitura Municipal de Campinas;

- ONGs pertencentes ao Conselho Municipal de Direitos da Criança e do Adolescente;

- Petrobras.

\section{Como a intersetorialidade ocorreu}

- Identificação de oito distritos de saúde da cidade com históricos de prostituição local e exploração sexual, com inserção de técnicos em saúde mental;

- Criação de uma equipe, com o apoio da população e 16 estudantes de graduação da UFSCar, para trabalhar com a temática de imagem (autoimagem):

- Implantação de diferentes centros de convivência para atividades culturais, de criação de renda e esportivas.

\section{Resultados}

- Aproximação do território, equipamento social, vínculo entre os participantes e a equipe técnica;

- Uso da máquina fotográfica de forma livre pelos participantes que descobriam seus territórios e histórias;

- Criação de rede de proteção contra exploração/violência sexual de crianças e adolescentes;

- Exposição dos resultados na Secretaria de Cultura do Município.

\section{Sperandio et al., 2006. Saúde ocular de crianças de 0 a 7 anos, Campinas (SP), 2003.}

Principais objetivos

- Construir, coletivamente, um projeto intersetorial na perspectiva da promoção da saúde, especificamente na área de saúde ocular.

\section{Setores/atores envolvidos \\ - Docentes da Unicamp: \\ - Discentes de $1^{\circ}$ ano do curso de \\ Medicina da Unicamp \\ - Agentes comunitários de saúde \\ (ACS); \\ - Moradores; \\ - Empresa Tecnol.} sores da creche e ACS; dores e ACS; Como a intersetorialidade ocorreu
- Reconhecimento do território e levanta-
mento das necessidades de saúde ocular
por questionários, entrevista com mora-
dores e ACS; estionários, entrevista com mora-

\section{Resultados}

- Diagnóstico da saúde ocular dos moradores do bairro, com aplicação de 96 testes visuais e identificação de 13 casos de deficiência visual, sendo oito encaminhados para tratamento; 
Quadro 1. (cont.)

\section{Como a intersetorialidade ocorreu}

- Banco de óculos, com armações doadas pela comunidade, por estudantes e pela empresa Tecnol, sendo a confecção de lentes realizada pela ótica da Unicamp.

\section{Resultados}

- Verificou-se a falta de informação sobre cuidados, desconhecimento das formas de prevenção das doenças, principalmente em crianças, e desconhecimento dos direitos dos usuários do SUS, em especial, no que diz respeito à saúde ocular;

- Aprendizado dos estudantes de medicina sobre como promover um projeto de promoção da saúde de acordo com princípios do SUS;

- Criação de banco de óculos no Centro de Saúde.

Magalhães Junior e Oliveira, 2006. Ac̣ões de combate à violência, Belo Horizonte (MG), de 2002 a 2006.

\begin{tabular}{|c|c|c|c|}
\hline $\begin{array}{l}\text { Principais objetivos } \\
\text { - Formular, acompa- } \\
\text { nhar e avaliar a Política } \\
\text { Municipal de enfren- } \\
\text { tamento à violência } \\
\text { doméstica e sexual; } \\
\text { - Desenvolver ações de } \\
\text { prevenção às violências } \\
\text { doméstica, sexual, no } \\
\text { trânsito e institucional; } \\
\text { - Construir uma rede } \\
\text { de atendimento e de } \\
\text { proteção social; } \\
\text { - Identificar os grupos } \\
\text { mais vulneráveis e } \\
\text { coletar informações } \\
\text { sobre pontos críticos de } \\
\text { acidentes no trânsito. }\end{array}$ & $\begin{array}{l}\text { Setores/atores envolvidos } \\
\text { - Prefeitura Municipal de Belo } \\
\text { Horizonte; } \\
\text { - Secretaria Municipal de Saúde; } \\
\text { - Secretaria Municipal de Trabalho e } \\
\text { Direitos de Cidadania; } \\
\text { - Secretaria Municipal de Políticas } \\
\text { Sociais; } \\
\text { - Sociedade civil com atuação na } \\
\text { área dos direitos humanos; } \\
\text { - Guarda Municipal; } \\
\text { - Empresa Municipal de Transporte } \\
\text { e Trânsito; } \\
\text { - Hospital Sara Kubitschek; } \\
\text { - Fundação Hospitalar do Estado } \\
\text { de MG; } \\
\text { - PUC-Minas; } \\
\text { - Faculdade Newton de Paiva; } \\
\text { - Companhia Brasileira de Trens } \\
\text { Urbanos; } \\
\text { - Secretaria de Estado de Saúde de } \\
\text { Minas Gerais; } \\
\text { - Liga Mineira do Trauma; } \\
\text { - ONG Rua Viva; } \\
\text { - Câmara Municipal de Belo Hori- } \\
\text { zonte; } \\
\text { - Mídia; } \\
\text { - Agentes comunitários de saúde; } \\
\text { - Hospitais conveniados; } \\
\text { - Servidores e profissionais da área } \\
\text { da saúde; } \\
\text { - Conselhos Tutelares; } \\
\text { - Associação Municipal de } \\
\text { Assistência Social; } \\
\text { - Unidades de Pronto Atendimento; } \\
\text { - Centros de Convivência da Saúde } \\
\text { Mental. }\end{array}$ & $\begin{array}{l}\text { Como a intersetorialidade ocorreu } \\
\text { - Reuniões regulares, oficinas de trabalho } \\
\text { e fóruns de discussão; } \\
\text { - Criação do Grupo de Trabalho da Vio- } \\
\text { lência Doméstica e Intradomiciliar e da } \\
\text { Comissão de Prevenção ao Acidente de } \\
\text { Trânsito (articulação permanente entre } \\
\text { Guarda Municipal e unidades de saúde); } \\
\text { - Criação da Comissão de Abordagem } \\
\text { à Violência e do Grupo de Trabalho da } \\
\text { Humanização; } \\
\text { - Pesquisa qualitativa para conhecer o } \\
\text { comportamento dos grupos mais vulne- } \\
\text { ráveis e do infrator contumaz, para orien- } \\
\text { tar abordagens direcionadas por parte da } \\
\text { prefeitura; } \\
\text { - Utilização das rádios comunitárias; } \\
\text { - Política de educação permanente; } \\
\text { - Mesa Permanente de Negociação do } \\
\text { SUS; } \\
\text { - Implantação dos colegiados em todos } \\
\text { os níveis de gestão da Secretaria Munici- } \\
\text { pal de Saúde. }\end{array}$ & $\begin{array}{l}\text { Resultados } \\
\text { - Elaboração do projeto Saúde na Paz; } \\
\text { - Implantação do protocolo de atendimento, } \\
\text { com as atribuições dos profissionais de saú- } \\
\text { de e agentes comunitários para identificação } \\
\text { de vítimas de violência; } \\
\text { - Publicação de um guia do usuário; } \\
\text { - Divulgação dos fluxos de encaminhamen- } \\
\text { tos e protocolos de atendimentos; } \\
\text { - Construção e reforma de unidades de } \\
\text { saúde, com cuidado para a acessibilidade de } \\
\text { pessoas com deficiência e idosos; } \\
\text { - Aquisição de equipamentos e mobiliários } \\
\text { para conforto de usuários e de trabalhadores } \\
\text { das unidades de saúde; } \\
\text { - Veiculação de mensagens educativas; } \\
\text { - Capacitação e sensibilização dos profis- } \\
\text { sionais da rede para identificar e atender às } \\
\text { vítimas de violência, principalmente da área } \\
\text { de saúde; } \\
\text { - Notificação das ocorrências e apoio aos } \\
\text { trabalhadores e gerentes vítimas de agres- } \\
\text { sões e ameaças. }\end{array}$ \\
\hline
\end{tabular}


Quadro 1. (cont.)

Padula et al., 2006. Intoxicação por chumbo em crianças, Bauru (SP), 2002 e 2003.

$\begin{array}{ll}\text { Principais objetivos } & \text { Setores/atores envolvidos } \\ \text { - Verificar as fontes de } & \text { - Secretaria de Estado da Saúde de } \\ \text { exposição ao chumbo; } & \text { São Paulo; } \\ \text { - Verificar a exposição } & \text { - Secretaria Municipal de Saúde; } \\ \text { humana (foco em } & \text { - Secretaria Municipal de Obras; } \\ \text { crianças de O a } 12 & \text { - Secretaria Municipal de Meio } \\ \text { anos); } & \text { Ambiente } \\ \text { - Identificar as neces- } & \text { - Secretaria Municipal das Adminis- } \\ \text { sidades de intervenção } & \text { trações Regionais; } \\ \text { com relação à saúde } & \text { - Ministério da Saúde; } \\ \text { humana e ao meio } & \text { - Companhia de Tecnologia de } \\ \text { ambiente; } & \text { Saneamento Ambiental; } \\ \text { - Efetuar as ações de } & \text { - Departamento de Água e Esgoto; } \\ \text { saneamento. } & \text { - Fundacentro; } \\ & \text { - Centro de Intoxicações (Unicamp); } \\ & \text { - Faculdades de Medicina e de } \\ & \text { Ciências (Unesp); } \\ & \text { - Faculdade de Odontologia (USP); } \\ & \text { - Hospital de Reabilitação de } \\ & \text { Anomalias Craniofaciais (USP). }\end{array}$

\section{Como a intersetorialidade ocorreu}

- Criação do Grupo de Estudo e Pesquisa da Intoxicação por Chumbo em Crianças de Bauru;

- Pesquisa de campo sobre a contaminação por chumbo em crianças num raio de $1 \mathrm{~km}$ ao redor da empresa contaminante;

- Avaliação clínica, laboratorial e radiográfica das crianças contaminadas; - Avaliação de amostras de água, hortifrutigranjeiros e leite da região;

- Ações de saneamento.

\section{Resultados}

- Interdição da empresa por tempo indeterminado;

- 314 crianças contaminadas detectadas e avaliadas;

- 23 casos graves tratados;

- Em três residências com piso de terra, cimentação do piso;

- Raspagem de $5 \mathrm{~cm}$ de solo superficial em 80 ruas de terra;

- Raspagem de $5 \mathrm{~cm}$ de solo superficial dos quintais de 270 residências;

- Aspirações de interiores de 164 residências;

- Limpeza e vedação de caixas d'água (117 visitas e 82 limpezas);

- Monitoramento de contaminações no lençol freático.

\section{Parreira et al., 2007. Projeto Ambientes Verdes e Saudáveis (PAVS), São Paulo (SP), de 2005 a 2007.}

\begin{tabular}{|c|c|}
\hline & Setores/atores envolvidos \\
\hline $\begin{array}{l}\text { - Fortalecer a gestão } \\
\text { integrada no nível local } \\
\text { para o desenvolvi- } \\
\text { mento de uma agenda } \\
\text { de proteção e de pro- } \\
\text { moção de ambientes } \\
\text { verdes e saudáveis; } \\
\text { - Desenvolver compe- } \\
\text { tências e habilidades } \\
\text { dos agentes comunitá- } \\
\text { rios de saúde; } \\
\text { - Intervir em questões } \\
\text { ambientais de forte } \\
\text { impacto sobre a saúde } \\
\text { da população; } \\
\text { - Formar agentes e } \\
\text { lideranças comunitá- } \\
\text { rias para abordagem } \\
\text { e elaboração de pro- } \\
\text { postas de intervenção } \\
\text { local; } \\
\text { - Adotar ações preven- } \\
\text { tivas e novas práticas } \\
\text { efetivas de promoção } \\
\text { da saúde. }\end{array}$ & $\begin{array}{l}\text { - Secretaria Municipal do Verde e } \\
\text { do Meio Ambiente; } \\
\text { - Secretaria Municipal de Saúde; } \\
\text { - Secretaria Municipal do Desen- } \\
\text { volvimento Social; } \\
\text { - Ministério da Saúde; } \\
\text { - Opas; } \\
\text { - Programa das Nações Unidas } \\
\text { para o Meio Ambiente; } \\
\text { - Faculdade Latino-Americana de } \\
\text { Ciências Sociais; } \\
\text { - Centro de Estudos, Pesquisa e } \\
\text { Documentação em Cidades Sau- } \\
\text { dáveis (USP); } \\
\text { - Fiocruz; } \\
\text { - Núcleo de Estudos da Saúde } \\
\text { Pública (UnB); } \\
\text { - Iclei Brasil; } \\
\text { - Fundação Oswaldo Cruz; } \\
\text { - Escola Técnica do SUS; } \\
\text { - Agentes Comunitários de Saú- } \\
\text { de, de controle de zoonoses e de } \\
\text { proteção social; } \\
\text { - Associação Congregação Santa } \\
\text { Catarina; } \\
\text { - Associação Saúde da Família; } \\
\text { - Associação Comunitária Monte } \\
\text { Azul; } \\
\text { - Casa de Saúde Santa Marcelina; } \\
\text { - Instituto Adventista de Ensino; } \\
\text { - Irmandade da Santa Casa de } \\
\text { Misericórdia de São Paulo; }\end{array}$ \\
\hline
\end{tabular}

\section{Como a intersetorialidade ocorreu \\ - Discussões coletivas, por meio de reuniões e encontros, e construção con- junta das próprias estratégias a serem implementadas;}

- Formação da equipe gestora do PAVS

\section{Resultados}

- Definição de Termos de Referência para orientar a seleção e a contratação dos membros da equipe;

- Realização do processo seletivo dos cinco coordenadores pedagógicos;

- Elaboração do Plano de Formação dos Educadores e dos Agentes, dirigido à qualificação dos 83 educadores contratados e dos 7.200 agentes envolvidos;

- Formatação do Plano de Formação dos Educadores e dos Agentes e discussão do mesmo por meio de cinco oficinas temáticas e reuniões técnicas. 
Quadro 1. (cont.)

Principais objetivos

\section{Setores/atores envolvidos}

Como a intersetorialidade ocorreu

\section{Resultados}

- Organização Santamarense de

Educação e Cultura;

- Sociedade Beneficente Israelita

Brasileira;

- Hospital Albert Einstein;

- Centro de Estudos e pesquisas

Dr. João Amorim;

- Fundação Zerbini;

- Centro Social Nossa Senhora do

Bom Parto.

Mori e Ogata, 2010. Projeto Produção de Cuidado Intersetorial, São Carlos (SP), 2008.

\section{Principais objetivos}

- Articular os serviços de saúde com outros equipamentos sociais; - Aumentar a adesão de famílias aos programas da UBS que só encaminham as crianças em situação de agravo (normalmente, a creche encaminha);

- Desenvolver e potencializar ações de educação em saúde entre uma equipe da Estratégia Saúde da Família e uma creche.

\section{Setores/atores envolvidos}

- Programa de Residência Multiprofissional da UFSCar;

- Direção de Educação Infantil;

- Ministério da Educação e Cultura;

- Creche envolvida na ação;

- Unidade Básica de Saúde envolvida na ação.

Freitas et al., 2011. Grupo Executivo para o controle de dengue, Belo Horizonte (MG), 2007 e 2008.

Principais objetivos

- Obter resultados mais efetivos no controle de dengue.

\section{Setores/atores envolvidos}

- Secretaria Municipal de Saúde;

- Secretaria Municipal de Planejamento;

- Secretaria Municipal de Educação;

- Secretaria Municipal de Políticas Urbanas;

-Secretaria Municipal de Políticas

Sociais;

- Superintendência de Limpeza

Urbana;

- Gabinete do Prefeito;

- Assessoria de Comunicação

Social;

- Secretarias municipais de administração regional;

- Gerências regionais de saúde;

- Gerência de Vigilância em Saúde

e Informação;

- Gerência de Vigilância Sanitária;

- Gerência de Controle de Zoonoses;

- Gerência de Epidemiologia;

- Gerência de Assistência.

\section{Como a intersetorialidade ocorreu}

- Visitas da equipe de saúde à creche para responder dúvidas e orientar as educadoras sobre doenças e problemas de saúde:

- Visitas da equipe de saúde para conhecer e acompanhar o trabalho das educadoras, que, posteriormente, foi transformado em oficinas;

- Reunião para ensinar as educadoras e a diretora sobre o funcionamento da UBS e da Estratégia Saúde da Família;

- Discussão sobre a situação de saúde e as condições de vida das crianças e mães.

\section{Resultados}

- Controle de surto de diarreia por meio de encaminhamento das crianças para a UBS e orientações sobre diarreia, desidratação, soro caseiro e medidas preventivas para as educadoras;

- Melhor encaminhamento em casos de doenças ou agravos e uso de guias de encaminhamento específicas para a creche, com espaço para a educadora descrever suas percepções, que são consideradas no momento das consultas;

- Manutenção da parceria e do planejamento de novas oficinas em conjunto (equipe de saúde e educadoras).

\section{Como a intersetorialidade ocorreu}

- Coordenação do grupo pelo Secretário

Municipal de Saúde;

- Regulação e limpeza urbanas pela Se-

cretaria Municipal de Políticas Urbanas

e respetiva secretaria de administração regional;

- Projetos especiais, na rede municipal de ensino, sobre o controle da dengue e discussão entre a escola e as famílias dos educandos pela Secretaria de Educação;

- Articulação junto aos setores externos à Prefeitura Municipal (governo estadual, setor privado, organizações da sociedade civil) pela Secretaria de Planejamento; - Realização de reuniões de grupo com os vários setores intervenientes, de 15 em 15 dias, para analisar a situação da dengue no município, para a definição de intervenções e responsabilidades, para a definição das ações conjuntas entre os diversos setores, nos casos necessários, e para a avaliação das ações realizadas.

\section{Resultados}

- Organização de mutirões de limpeza para o 'lixo da dengue' (objetos que acumulam água): em 2007, houve recolhimento de 489 toneladas de lixo; em 2008, foram retiradas 2.379 toneladas;

- Limpeza e capinamento de áreas públicas e privadas: em 2007, foram limpos e capinados 360.000 m2; em 2008, 674.383 m2.

- Geração de emprego para 124 agentes comunitários de limpeza urbana;

- Fiscalização em imóveis fechados;

- Realização de ações específicas do setor saúde, como modificações de alguns protocolos;

- Realização de ações de educação;

- Realização de ações de mobilização e de comunicação. 
Quadro 1. (cont.)

Palácios et al., 2012. Projeto Hortas Comunitárias, Maringá (PR), de 2005 a 2011.

\begin{tabular}{llll}
\hline Principais objetivos & Setores/atores envolvidos & Como a intersetorialidade ocorreu & Resultados \\
- Possibilitar a geração & - Secretaria Municipal de Serviços & - Coordenação pela Secretaria Municipal & - 21 hortas comunitárias; \\
de renda; & Públicos; & de Serviços Públicos; & - Relatos de melhorias nas saúdes física e \\
- Incentivos à alimen- & - Secretaria Municipal de Saúde; & - Reuniões com moradores dos bairros & mental, diminuição do consumo de medica- \\
tação saudável; & - Presidente do bairro; & atendidos; & mentos e aumento da sociabilidade; \\
- Ocupar de forma & - Centro de Referência em Assis- & - Obras de infraestrutura e implantação & - Participação de 600 famílias, beneficiando \\
benéfica terrenos bal- & tência Social; & tecnológica pela Secretaria Municipal de & cerca de 2.400 pessoas; \\
dios ociosos em áreas & - Unidades Básicas de Saúde; & Serviços Públicos, Secretaria de Saúde e & - Produção anual estimada em 200 tone- \\
urbanas; & - Eletrosul Centrais Elétricas; & Companhia de Saneamento do Paraná; & ladas de verduras e legumes, isentos de \\
- Reduzir a criminalida- & - Rotary Club Maringá Sul; & - Assistência técnica por equipe técnica & agrotóxicos; \\
de entre os jovens; & - Companhia de Saneamento do & da Prefeitura e Centro de Referência em & - Contribuição financeira da comercialização \\
- Combater a depres- & Paraná; & Agricultura Urbana e Periurbana, orien- & da produção excedente ao consumo, po- \\
são e baixa autoestima & - Centro de Referência em Agricul- & tando e monitorando todos os trabalhos; & dendo ter uma significativa participação na \\
de idosos; & tura Urbana e Periurbana (Univer- & - Demais parceiros: cessão dos espaços & renda familiar. \\
- Melhorar a qualidade & sidade Estadual de Maringá); & e financiamento da infraestrutura; & \\
de vida e saúde de & - Agência Adventista de Desenvol- & - Comunidade executa as atividades de & \\
comunidades pobres. & vimento e Recursos Assistenciais; & produção e manutenção dos canteiros. & \\
& - Profissionais liberais e comer- & & \\
& ciantes. & &
\end{tabular}

Fonte: Elaboração própria

Os estudos incluídos nesta revisão apresentam importantes contribuições da intersetorialidade para a população e para o enfrentamento dos problemas que pretendiam resolver, pois trazem estratégias que são planejadas de forma compartilhada e de acordo com a necessidade sentida. Podem contribuir para a melhoria da qualidade de vida da população à qual são destinadas, respondendo às necessidades de saúde de uma coletividade, mobilizando os setores necessários para realizar essas ações (CAMPOS; BARROS; CASTRO, 2004). Uma parte da importância de se trabalhar de forma intersetorial está relacionada com a amplitude e a magnitude das ações. Os projetos alcançaram um grande número de pessoas, abrangeram diversos temas, diferentes territórios, realizaram processos educativos e informativos, com mudanças muitas vezes ambientais, mobilização comunitária, e ampliaram a discussão sobre cidadania e direitos constitucionais, também havendo uma preocupação do poder público em buscar alternativas de articulação e parcerias com outros setores.

Todas as experiências relatadas tiveram o município ou uma localidade intramunicipal como território. No entanto, é interessante notar que em duas experiências (MAGALHÃES JUNIOR; OLIVEIRA, 2006; PADULA ET AL., 2006) houve parceria com a Secretaria de Estado da Saúde, e em cinco (CARNEIRO; GOMES, 2004; LOPES; MALFITANO, 2006; PADULA ET AL., 2006; PARREIRA; SOUSA; NEVES, 2007; MORI; OGATA, 2010) Os Ministérios da Saúde ou da Educação e Cultura foram apontados como atores envolvidos na ação. Em um dos casos (PARREIRA; SOUSA; NEVES, 2007), referente à implantação do Projeto Ambientes Verdes e Saudáveis, no município de São Paulo, houve também a participação de entidades supranacionais, como a Organização Panamericana de Saúde e as Nações Unidas.

Excetuando o setor saúde (por conta da natureza dos projetos levantados), o setor educação é o que mais aparece vinculado às ações intersetoriais levantadas, dez (CARNEIRO; GOMES, 2004; DOBASHI ET AL., 2005; LOPES; MALFITANO, 2006; MAGALHÃES JUNIOR; OLIVEIRA, 2006; PADULA ET AL., 2006; SPERANDIO ET AL., 2006; PARREIRA; SOUSA; NEVES, 2007; MORI; OGATA, 2010; FREITAS; RODRIGUES; ALMEIDA, 2011; PALÁCIOS ET AL., 2012), o que reforça a sua importância no âmbito da promoção da saúde. Ao se considerar, especificamente, as escolas, é possível ver que são espaços potenciais de 
transformações sociais e de construção de conhecimentos e valores, facilitando toda e qualquer atividade de promoção da saúde e de redução de vulnerabilidades, sejam estas de ordem individual, social ou institucional, como, por exemplo, a intervenção em situações de violência que coloquem em risco o crescimento e o desenvolvimento pleno de crianças e adolescentes.

No mais, organizações do terceiro setor apareceram em seis projetos (BECKER ET AL., 2004; DOBASHI ET AL., 2005; LOPES; MALFITANO, 2006; MAGALHÃES JUNIOR; OLIVEIRA，2006; PARREIRA; SOUSA; NEVES, 2007; PALÁCIOS ET AL., 2012). Por outro lado, os moradores do território apareceram explicitamente como atores envolvidos somente em quatro (BECKER ET AL., 2004; CARNEIRO; GOMES, 2004; SPERANDIO ET AL., 2006; PALÁCIOS ET AL., 2012) das onze ações revisadas.

Percebe-se que os artigos consideraram a intersetorialidade uma estratégia essencial para se promover saúde; no entanto, nenhum deles explicita em qual definição de intersetorialidade o projeto se embasa, o que revela importante lacuna. Por outro lado, algumas características dos projetos são mais comumente citadas, desvelando as crenças dos autores sobre o que seriam projetos intersetoriais. Costuma-se caracterizar o projeto como um conjunto de ações com diferentes participações, enfatizando as redes de compromisso, a corresponsabilidade e a cooperação de distintos setores. Também é comum a citação de espaços coletivos para discussão, o compartilhamento de saberes com horizontalidade e a integração de diferentes profissionais para o planejamento de ação em conjunto, articulado e contínuo durante os programas.

As formas de se operacionalizar a intersetorialidade variaram de acordo com o objetivo, a amplitude e a complexidade das ações pretendidas. De modo geral, percebem-se a utilização de reuniões regulares entre os atores envolvidos, a realização de uma ou mais etapas diagnósticas para entender o problema em questão, em dois casos, envolvendo a participação dos próprios moradores do território na coleta dos dados (BECKER ET AL., 2004; CARNEIRO; GOMES, 2004), O desenvolvimento conjunto das estratégias a serem implantadas e a criação de grupos de trabalho.

Percebe-se que algumas das dificuldades encontradas para a operacionalização da intersetorialidade são, ao menos em parte, consequências do modelo de intersetorialidade que se adota: ascendente ou descendente. Segundo Nascimento (2010), a intersetorialidade ascendente ocorre quando os representantes da gestão, que são a cúpula administrativa, articulam-se e se integram para atingir ações de metas únicas, que serão aplicadas em âmbito local. Já a intersetorialidade descendente é caracterizada como uma atuação que surge da base da gestão, dos sujeitos/técnicos de organismos públicos e da sociedade civil, que formula propostas para conduzir as ações. A intersetorialidade ascendente, mais comum entre os documentos analisados, além de reduzir a participação popular, dá maior margem às disputas de poder nos diferentes níveis de governo, que, em função de mudanças na sua condução, tornam vulneráveis as instituições pela descontinuidade de políticas em curso e pela tendência de traçar ações identificadas com a nova equipe gestora (MACHADO; PORTO, 2003).

É interessante notar que os artigos selecionados somente descrevem as ações dos projetos, faltando comparação com outras estratégias ou projetos similares. Ademais, não são todos os manuscritos que apresentaram resultados finalísticos das ações, ou seja, que avaliaram o impacto da ação sobre o problema-alvo, o alcance dos objetivos e suas implicações em médio ou longo prazo. Por vezes, os autores consideraram como resultados as propostas futuras, e houve dificuldade em se avaliar o impacto do trabalho intersetorial. A avaliação vai além da descrição da ação, e as razões para a incompletude desse item, tão importante para analisar o impacto das ações, residem no 
fato de a intersetorialidade ocorrer em diferentes níveis, de os objetivos dos projetos se transformarem durante o processo, de haver dificuldades em negociar e decidir quais questões são prioritárias - por incompatibilidade e diferenças das agendas entre os diferentes agentes - e de os resultados sofrerem interferência em função de disputas políticas e interesses eleitorais (MAGALHÃES; BODSTEIN, 2009).

Por outro lado, resultados intermediários e decorrentes de avaliações do processo de implantação da ação são mais comuns. Vale destacar que nenhum dos trabalhos encontrados apresentou os resultados planejados, mas não alcançados, ou mesmo se referiu a experiências sem êxito. Dados sobre capacidade de sustentabilidade econômica, política etc., importantes para a avaliação de uma ação de longo prazo, não foram apresentados.

Observou-se que em seis artigos (BECKER ET AL., 2004; CARNEIRO; GOMES, 2004; MAGALHÃES JUNIOR; OLIVEIRA, 2006; PARREIRA; SOUSA; NEVES, 2007; MORI; OGATA, 2010; PALÁCIOS ET AL., 2012) houve uma proposta de continuidade do projeto desenvolvido, frequentemente, para a sua ampliação. Este é um dado relevante, uma vez que a continuidade de políticas de promoção de saúde é importante por estas envolverem processos coletivos de transformação, com impactos em médio e longo prazos (Sícoli; NASCIMENTO, 2003). No entanto, não ficou claro nos artigos analisados como a sustentabilidade do projeto será operacionalizada. Existe uma ideia do que se pretende e propõe realizar, porém, sem apresentar, concretamente, por exemplo, os próximos passos, a consolidação de parcerias e suas funções, compromissos de reuniões periódicas e de financiamento. Ademais, nenhum dos artigos lidos reportava ser sobre a continuação de uma iniciativa ou a segunda fase de um projeto de promoção de saúde. Parecem ser mais iniciativas pontuais ou iniciais, sem informações sobre 'frutos' que se prolonguem no tempo.

Vale destacar que a sustentabilidade de ações de promoção de saúde equaciona fatores diversos, sendo central a questão econômica. Como referem Sícoli e Nascimento (2003, P. 118):

[...] o desenvolvimento sustentável pressupõe considerar a viabilidade econômica e ambiental das ações e iniciativas. Está ligado à busca de alteração do modelo predatório de desenvolvimento, à ampliação de práticas educativas e ao fortalecimento do sentimento de co-responsabilização e instituição de valores éticos.

Nesse sentido, promover a saúde de forma integrada com a população e com os setores das esferas federal, estadual e municipal é mais vantajoso economicamente do que investir unicamente na resolução dos problemas. Então, por que deixar os projetos de lado depois de terem sido iniciados, depois de ter havido a junção de objetivos e de parcerias e de terem sido demonstrados resultados iniciais? Em seis artigos revisados (CARNEIRO; GOMES, 2004; LOPES; MALFITANO, 2006; MAGALHÃES JUNIOR; OLIVEIRA, 2006; PADULA ET AL., 2006; PARREIRA; SOUSA; NEVES, 2007; MORI; OGATA, 2010), verificou-se a participação de entidades estaduais e/ou federais, e em apenas um (CARNEIRO; GOMES, 2004) foi encontrada referência à evolução do projeto. Os projetos restantes apenas mencionaram o seu tempo de atuação ou ser parte de uma primeira fase de implantação. Parece, então, haver um conjunto de projetos com apoios pontuais de instituições públicas e, portanto, com alcance muito limitado no tempo. Mas qual a possibilidade de real impacto se a maioria das propostas em andamento no País se restringe a projetos ou parcerias transitórias? Muitos projetos se tornam pontuais porque não lhes é garantida a continuidade, em virtude, sobretudo, do financiamento. Isso acaba por ocasionar experiências que não chegam a se consolidar, produzindo impactos bastante restritos no tocante às problemáticas para as quais 
direcionaram sua atenção. Essa é uma realidade para a maioria dos projetos sociais no Brasil, atualmente (LOPES; MALFITANO, 2006).

Por fim, vale apontar duas características das publicações em si. Dos onze artigos, oito se referem a ações ocorridas na região Sudeste (BECKER ET AL., 2004; LOPES; MALFITANO, 2006; MAGALHÃES JUNIOR; OLIVEIRA, 2006; PADULA ET AL., 2006; SPERANDIO ET AL., 2006; PARREIRA; SOUSA; NEVES, 2007; MORI; OGATA, 2010; FREITAS; RODRIGUES, ALMEIDA, 2011) e um nas regiões Sul (PALÁCIOS ET AL., 2012), Nordeste (CARNEIRO; GOMES, 2004) e CentroOeste (DOBASHI ET AL., 2005). Isso pode indicar que a intersetorialidade ainda é uma prática ou pouco desenvolvida nas demais regiões ou pouco compartilhada no meio acadêmico. A segunda hipótese parece mais plausível aos autores deste manuscrito, uma vez que tais práticas normalmente nascem e se desenvolvem nos serviços à população, setor em que a publicação acadêmica das experiências e dos resultados não é um produto tão importante. Talvez tal escassez indique que a academia precise ir mais a campo conhecer as experiências e que os operadores de políticas públicas sejam incentivados a publicizar suas experiências intersetoriais.

A segunda característica das publicações que merece destaque é o fato de que cinco manuscritos (CARNEIRO; GOMES, 2004; DOBASHI ET AL., 2005; MAGALHÃES JUNIOR; OLIVEIRA, 2006; PARREIRA; SOUSA; NEVES, 2007; PALÁCIOS ET AL., 2012) foram publicados no periódico Divulgação em Saúde para Debate, editado e distribuído pelo Centro Brasileiro de Estudos de Saúde (Cebes). Talvez isso tenha ocorrido por conta de sua política editorial e seu escopo, uma vez que pretende difundir o conhecimento produzido na experiência cotidiana dos sistemas municipais de saúde, divulgando documentos resultantes de eventos promovidos por instituições ou entidades do setor saúde (CEBES, 2014). Isso pode indicar a necessidade de mais espaço nos periódicos científicos da área para o relato de tais experiências.

Ao considerar os resultados desta revisão, é necessário lembrar que somente uma base de referências foi utilizada para a busca. Apesar da atual abrangência da base Lilacs mais de 850 periódicos e de 650 mil registros, em março de 2013 - é possível que alguns artigos disponíveis somente em outras bases não tenham sido avaliados quanto à sua elegibilidade para esta revisão. Por outro lado, não é do conhecimento dos autores trabalho similar sobre o tema, e acredita-se que os resultados aqui apresentados oferecem um bom panorama sobre as ações intersetoriais recentes.

\section{Considerações finais}

O escopo deste estudo foi a identificação de artigos nacionais sobre programas intersetoriais que envolvessem o setor saúde. Todos consideraram a intersetorialidade como fundamental para a promoção da saúde, mas nenhum deles explicitou a definição de intersetorialidade em que se embasaram. Assim, a partir desta revisão se pode concluir que as ações intersetoriais realizadas nos primeiros anos do século atual ainda parecem incipientes no Brasil, se considerarmos os trabalhos publicados em periódicos científicos, no que diz respeito à sua descrição, execução e avaliação. As experiências relatadas indicam a grande potencialidade desse tipo de ação para o enfrentamento de problemas em saúde pública, tendo como partida a visão ampliada do processo saúde-doença, bem como para a promoção da saúde em nosso País. Em todas as iniciativas, pelo menos quatro serviços ou setores foram envolvidos. O setor educação foi um grande parceiro nessas ações, e as Instituições de Ensino Superior participaram de sete delas.

Todos os estudos apresentam o potencial das ações intersetoriais para a transformação da realidade local e dos serviços, mas as experiências analisadas carecem de informações sobre sua continuidade e, portanto, da sustentabilidade dos programas. 
Ações intersetoriais deveriam ser resultantes ou, ainda, ter grande potencial para o desenvolvimento de políticas públicas. O acompanhamento dessas experiências possibilitariam verificar a transformação desse potencial em resultados duradouros do ponto de vista dos serviços e de seus participantes. Ressaltamos, ainda, a importância de uma contínua avaliação dessas iniciativas, do compartilhamento das experiências, das estratégias de avaliação e de busca de sustentabilidade, utilizadas visando à efetiva concretização das mudanças de médio e longo prazos.

É imprescindível o desenvolvimento de um olhar e de um fazer intersetoriais, em que os vários atores e setores dialoguem, tendo como norte as necessidades da população e a perspectiva de desenvolvimento de políticas públicas duradouras.

\section{Referências}

BECKER, D. et al. Empowerment e avaliação participativa em um programa de desenvolvimento local e promoção da saúde. Ciência \&t Saúde Coletiva, Rio de Janeiro, v. 9, n. 3, p. 655-667, 2004.

BUSS, P. M. Promoção da saúde e qualidade de vida. Ciência \& Saúde Coletiva, Rio de Janeiro, v. 5, n. 1, p. 163-177, 2000.

CAMPOS, G. W.; BARROS, R. B.; CASTRO, A. M. Avaliação de política nacional de promoção da saúde. Ciência \&t Saúde Coletiva, Rio de Janeiro, v. 9, n. 3, p. 745-749, 2004

CARNEIRO, A. O.; GOMES, N. P. Ações intersetoriais para a promoção da saúde. Divulgação em Saúde para Debate, Rio de Janeiro, n. 30, p. 88-90, 2004.

\section{CENTRO BRASILEIRO DE ESTUDOS DE SAÚDE.}

Divulgação em Saúde para Debate. Disponível em: <http:// cebes.com.br/publicacao-tipo/revista-divulgacao/>. Acesso em: 05 nov. 2014.

COUTO, M. C. V.; DELGADO, P. G. G. Intersetorialidade: uma exigência da clínica com crianças na atenção psicossocial: considerações preliminares. In: LAURIDSEN-RIBEIRO, E.; TANAKA, O. Y. (Ed.). Atenção em saúde mental para crianças e adolescentes no SUS. São Paulo: Hucitec, 2010.

DALMOLIN, B. B. et al. Significados do conceito de saúde na perspectiva de docentes da área da saúde. Escola Anna Nery Revista de Enfermagem, Rio de Janeiro, v. 15, n. 2, p. 389-394, 2011.

DOBASHI, B. F. et al. Viva Seu Bairro: em Campo Grande/MS a promoção da saúde percorre os caminhos da intersetorialidade. Divulgação em Saúde para Debate, Rio de Janeiro, n. 32, p. 28-35, 2005.

FREITAS, R. M.; RODRIGUES, C. S.; ALMEIDA, M. C. M. Estratégia intersetorial para o controle da dengue em Belo Horizonte (Minas Gerais), Brasil. Saúde e Sociedade, São Paulo, v. 20, n. 3, p. 773-785, 2011.

HIGGINS, J. P. T.; GREEN, S. Cochrane handbook for systematic reviews of interventions - version 5.1.0., 2011. Disponível em: <http://handbook.cochrane.org>. Acesso em: 05 nov. 2014. 
INOJOSA, R. M. Sinergia em políticas e serviços públicos: desenvolvimento social com intersetorialidade. Cadernos Fundap, São Paulo, n. 22, p. 102-110, 2001.

JUNQUEIRA, L. A. P. Intersetorialidade, transetorialidade e redes sociais na saúde. Revista de Administração Pública, Rio de Janeiro, v. 34, n. 6, p. 35-45, 2000.

Novas formas de gestão na saúde: descentralização e intersetorialidade. Saúde e Sociedade, São Paulo, v. 6, n. 2, p. 31-46, 1997.

LILACS. Disponível em: <http://lilacs.bvsalud.org>. Acesso em: 05 nov. 2014.

LOPES, R. E.; MALFITANO, A. P. S. Ação social e intersetorialidade: relato de uma experiência na interface entre saúde, educação e cultura. Interface Comunicação, Saúde, Educação, Botucatu, v. 10, n. 20, p. 505-515, 2006.

MACHADO, J. M. H.; PORTO, M. F. S. Promoção da saúde e intersetorialidade: a experiência da vigilância em saúde do trabalhador na construção de redes. Epidemiologia e Serviços de Saúde, Brasília, v. 12, n. 3, p. 121-130, 2003.

MAGALHÃES JUNIOR, H. M.; OLIVEIRA, R. C. A violência urbana em Belo Horizonte: o olhar da saúde e as possibilidades de intervenção intersetorial. Divulgação em Saúde para Debate, Rio de Janeiro, n. 35, p. 92-99, 2006.

MAGALHÃES, R.; BODSTEIN, R. Avaliação de iniciativas e programas intersetoriais em saúde: desafios e aprendizados. Ciência \& Saúde Coletiva, Rio de Janeiro, v. 14, n. 3, p. 861-868, 2009.

MENDES, E. Uma agenda para a saúde. São Paulo: Hucitec, 1996.

MENDES, R.; ACKERMAN, M. Intersetorialidade: reflexões e práticas. In: FERNANDES, J.; MENDES, R. (Ed.). Promoção da saúde e gestão local. São Paulo: CEPEDOC, 2007

MORI, A. Y.; OGATA, M. N. Cuidado intersetorial: promovendo a articulação entre a Equipe de Saúde da
Família e uma creche. Revista de APS: Atenção Primária à Saúde, Juiz de Fora, v. 13, n. 4, p. 518-522, 2010.

NARVAI, P. C.; FRAZÃO, P. Práticas de saúde pública. In: ROCHA, A. A.; CESAR, C. L. G. (Ed.). Saúde pública: bases conceituais. São Paulo: Atheneu, 2008. p. 269-295.

NASCIMENTO, S. Reflexões sobre a intersetorialidade entre as políticas públicas. Serviço Social \&t Sociedade, São Paulo, n. 101, p. 95-120, 2010.

PADULA, N. A. M. et al. Intoxicação por chumbo e saúde infantil: ações intersetoriais para o enfrentamento da questão. Cadernos de Saúde Pública, Rio de Janeiro, v. 22, n. 1, p. 163-171, 2006.

PALÁCIOS, A. R. O. et al. O projeto Hortas Comunitárias no município de Maringá. Divulgação em Saúde para Debate, Rio de Janeiro, n. 48, p. 33-41, 2012.

PARREIRA, C.; SOUSA, M. F.; NEVES, H. Projeto Ambientes Verdes e Saudáveis: integrando políticas públicas na cidade de São Paulo. Divulgação em Saúde para Debate, Rio de Janeiro, n. 39, p. 59-67, 2007.

PORTO, M. F. S.; LACAZ, F. A. C.; MACHADO, J. M. H. Promoção da saúde e intersetorialidade: contribuições e limites da vigilância em saúde do trabalhador no Sistema Único de Saúde (SUS). Saúde em Debate, Rio de Janeiro, v. 27, n. 65, p. 192-206, 2003.

SÍCOLI, J. L.; NASCIMENTO, P. R. Promoção de saúde: concepções, princípios e operacionalização. Interface - Comunicação, Saúde, Educação, Botucatu, v. 7, n. 12, p. 101-22, 2003.

SPERANDIO, A. M. G. et al. A universidade colaborando na construção de um projeto de promoção da saúde: relato de experiência de um grupo de alunos de medicina da Unicamp, Campinas, SP, Brasil. Revista Brasileira de Educação Médica, Rio de Janeiro, v. 30, n. 6, p. 200-208, 2006.

Recebido para publicação em dezembro de 2013

Versão final em outubro de 2014

Conflito de interesses: inexistente

Suporte financeiro: não houve 